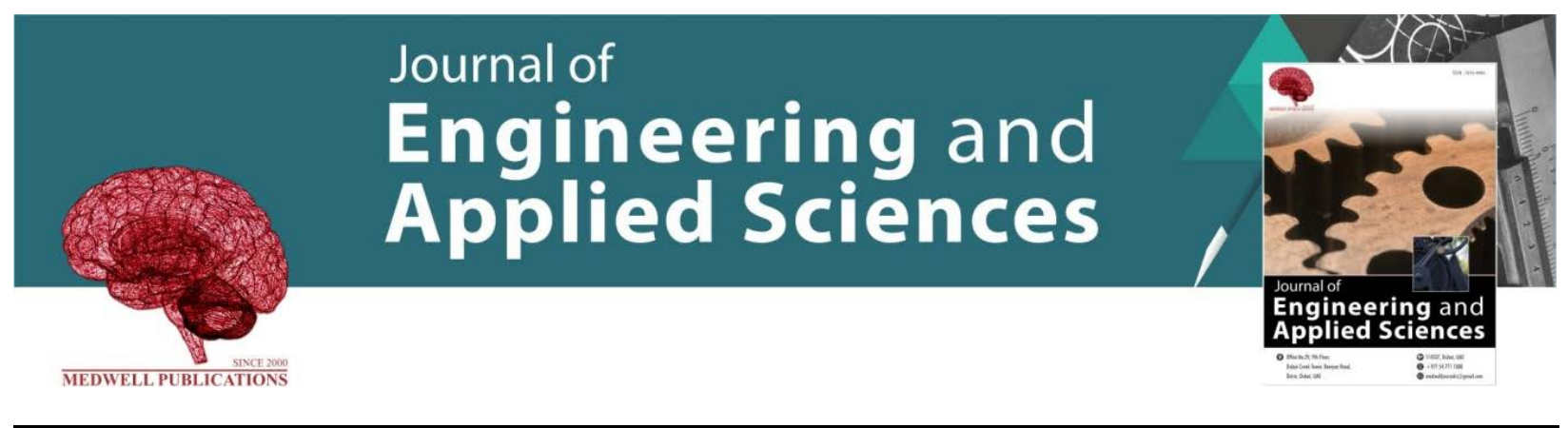

\title{
Position and Speed Control of 2DOF Industrial Robotic Arm using Robust Controllers
}

Mustefa Jibril, Messay Tadese and Reta Degefa

School of Electrical and Computer Engineering, Dire Dawa Institute of Technology, Dire Dawa, Ethiopia

Key words: Industrial robotic arm, Mixed $\mathrm{H} 2 / \mathrm{H} \infty$ synthesis with regional pole placement controller, H2 optimal controller

\section{Corresponding Author:}

Mustefa Jibril

School of Electrical and Computer Engineering, Dire Dawa Institute of Technology, Dire Dawa, Ethiopia

Page No.: 3765-3769

Volume: 15, Issue 24, 2020

ISSN: 1816-949x

Journal of Engineering and Applied Sciences

Copy Right: Medwell Publications
Abstract: In this study, a 2 DOF industrial robotic arm is designed and simulated for elbow and wrist angle and velocity performance improvement using robust control method. Mixed $\mathrm{H} 2 / \mathrm{H} \infty$ synthesis with regional pole placement and $\mathrm{H} 2$ optimal controllers are used to improve the system output. The open loop response of the robot arm shows that the elbow and wrist angles and velocities need some improvement. Comparison of the proposed controllers for an impulse and step input signals have been done and a promising results have been obtained.

\section{INTRODUCTION}

A robotic arm is a makes of mechanical arm, usually programmable with similar functions to a human arm; the system may be the sum total of the mechanism or may be segment of a more complex robot. The links of such a system are connected by joints allowing either as articulated robot or linear displacement robot ${ }^{[1]}$. The links of the robot can be considered to form a kinematic chain. The overall system of the kinematic chain of the manipulator is called the end effector and it is analogous to the human arm. However, the assembly "robotic hand" as a synonym of the robotic arm is often proscribed $^{[2]}$.

\section{MATERIALS AND METHODS}

Mathematical modeling of the robot arm: The 2 DOF industrial robot arm can be modeled as shown in Fig. 1. The equation of motion at the elbow is:

$$
\mathrm{J}_{1} \ddot{\theta}_{1}+\mathrm{B} \dot{\theta}_{1}+\mathrm{K} \theta_{1}-\mathrm{B} \dot{\theta}_{2}-\mathrm{K} \theta_{2}=\mathrm{T}=\mathrm{K}_{\mathrm{T}} \mathrm{i}
$$

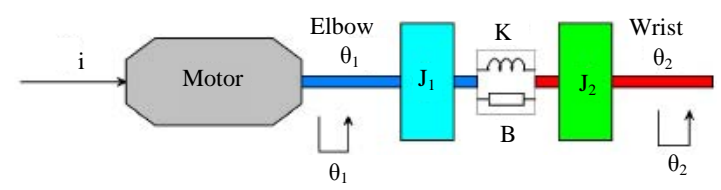

Fig. 1: Industrial robot arm design

The equation of motion at the wrist is:

Let:

$$
\mathrm{J}_{2} \ddot{\theta}_{2}+\mathrm{B} \dot{\theta}_{2}+\mathrm{K} \theta_{2}-\mathrm{B} \dot{\theta}_{1}-\mathrm{K} \theta_{1}=0
$$

$$
\mathrm{x}_{1}=\theta_{1}, \mathrm{x}_{2}=\dot{\theta}_{1}, \mathrm{x}_{3}=\theta_{2}, \mathrm{x}_{4}=\dot{\theta}_{2} \text { and } \mathrm{i}=\mathrm{u}
$$

So, the state space representation becomes:

$$
\left[\begin{array}{l}
\dot{\mathrm{x}}_{1} \\
\dot{\mathrm{x}}_{2} \\
\dot{\mathrm{x}}_{3} \\
\dot{\mathrm{x}}_{4}
\end{array}\right]=\left(\begin{array}{cccc}
0 & 1 & 0 & 0 \\
-\frac{\mathrm{K}}{\mathrm{J}_{1}} & -\frac{\mathrm{B}}{\mathrm{J}_{1}} & \frac{\mathrm{K}}{\mathrm{J}_{1}} & \frac{\mathrm{B}}{\mathrm{J}_{1}} \\
0 & 0 & 0 & 1 \\
\frac{\mathrm{K}}{\mathrm{J}_{2}} & \frac{\mathrm{B}}{\mathrm{J}_{2}} & -\frac{\mathrm{K}}{\mathrm{J}_{2}} & -\frac{\mathrm{B}}{\mathrm{J}_{2}}
\end{array}\right]\left[\begin{array}{l}
\mathrm{x}_{1} \\
\mathrm{x}_{2} \\
\mathrm{x}_{3} \\
\mathrm{x}_{4}
\end{array}\right]+\left[\begin{array}{l}
0 \\
\frac{\mathrm{K}_{\mathrm{T}}}{\mathrm{J}_{1}} \\
0 \\
0
\end{array}\right] \mathrm{u}
$$


Table 1: System parameters

\begin{tabular}{lcl}
\hline Parameters & Symbols & Values \\
\hline Moment of inertia of the elbow & $\mathrm{J}_{1}$ & $3 \mathrm{kgm}^{2} / \mathrm{s}^{2}$ \\
Moment of inertia of the wrist & $\mathrm{J}_{2}$ & $2 \mathrm{kgm}^{2} / \mathrm{s}^{2}$ \\
Damping coefficient of the system & $\mathrm{B}$ & $8 \mathrm{~N} . \mathrm{s} / \mathrm{m}$ \\
Spring stiffness of the system & $\mathrm{K}$ & $6 \mathrm{~N} / \mathrm{m}$ \\
Torque constant & $\mathrm{K}_{\mathrm{T}}$ & $4 \mathrm{Nm} / \mathrm{A}$ \\
\hline
\end{tabular}

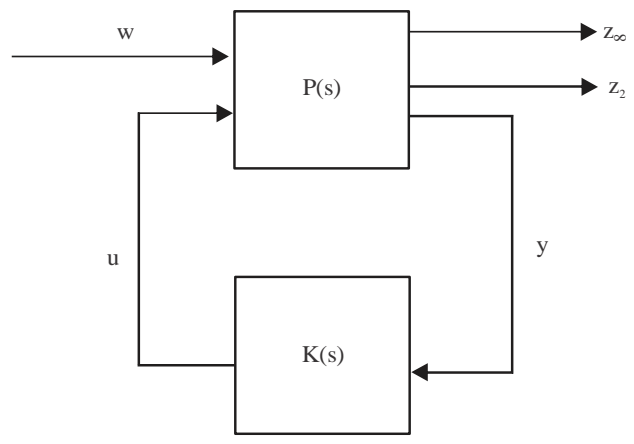

Fig. 2: Mixed $\mathrm{H} 2 / \mathrm{H} \infty$ configuration

$$
y=\left(\begin{array}{llll}
1 & 0 & 0 & 0 \\
0 & 1 & 0 & 0 \\
0 & 0 & 1 & 0 \\
0 & 0 & 0 & 1
\end{array}\right)\left[\begin{array}{l}
x_{1} \\
x_{2} \\
x_{3} \\
x_{4}
\end{array}\right]
$$

The system parameters are shown in Table 1 . The state space numerically becomes:

$$
\begin{aligned}
& {\left[\begin{array}{l}
\dot{x}_{1} \\
\dot{x}_{2} \\
\dot{x}_{3} \\
\dot{x}_{4}
\end{array}\right]=\left(\begin{array}{cccc}
0 & 1 & 0 & 0 \\
-2 & -2.67 & 2 & 2.67 \\
0 & 0 & 0 & 1 \\
3 & 4 & -3 & -4
\end{array}\right)\left[\begin{array}{l}
x_{1} \\
x_{2} \\
x_{3} \\
x_{4}
\end{array}\right]+\left[\begin{array}{l}
0 \\
1.3 \\
0 \\
0
\end{array}\right] u } \\
& y=\left(\begin{array}{llll}
1 & 0 & 0 & 0 \\
0 & 1 & 0 & 0 \\
0 & 0 & 1 & 0 \\
0 & 0 & 0 & 1
\end{array}\right)\left[\begin{array}{l}
x_{1} \\
x_{2} \\
x_{3} \\
x_{4}
\end{array}\right]
\end{aligned}
$$

\section{Proposed controller design}

Mixed $\mathbf{H} 2 / \mathrm{H}_{\infty}$ with regional pole placement controller design: The mixed $\mathrm{H} 2 / \mathrm{H} \infty$ control problem is to minimize the $\mathrm{H} 2$ rule of overall state feedback output gains $\mathrm{k}$ and also satisfies the $\mathrm{H} \infty$ norm gain. Mixed $\mathrm{H} 2 / \mathrm{H} \infty$ synthesis with regional pole placement is one of the main example of multi-objective design by using the LMI approach. The mixed $\mathrm{H} 2 / \mathrm{H}^{\infty}$ synthesis with regional pole placement is sketched in Fig. 2. The output of the system $\mathrm{z}$ is associated with the $\mathrm{H} \infty$ achievement while the output $\mathrm{z} 2$ is associated with the $\mathrm{H} 2$ performance. The industrial robot arm with mixed $\mathrm{H} 2 / \mathrm{H} \infty$ controller block diagram is shown in Fig. 3.

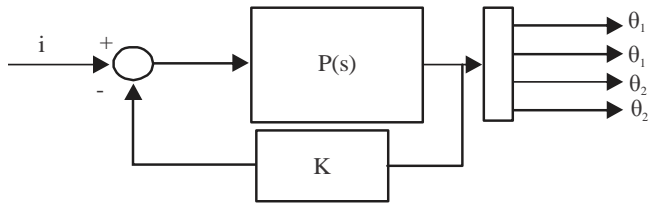

Fig. 3: Industrial robot arm with mixed $\mathrm{H} 2 / \mathrm{H} \infty$ controller block diagram

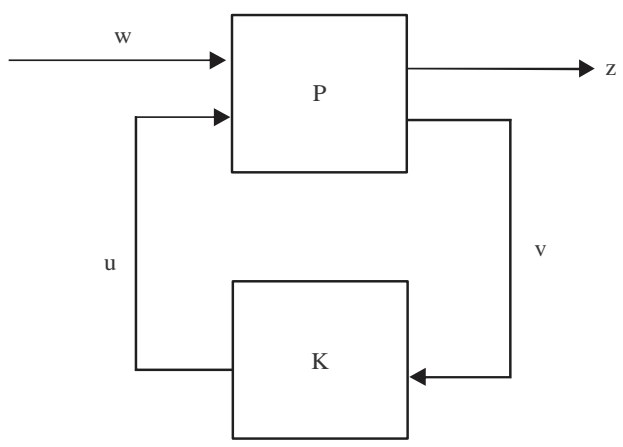

Fig. 4: General control configuration

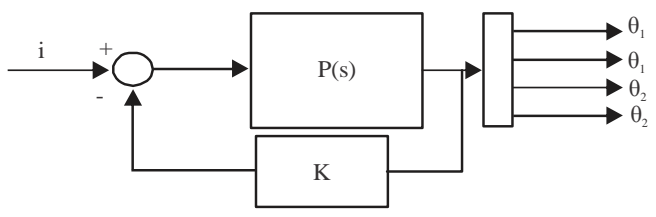

Fig. 5: Industrial robot arm with H2 optimal controller block diagram

H2 optimal controller design: There are many track in which feedback design problems can be cast as $\mathrm{H} 2$ optimization problems. It is very useful therefore to have a ancestor funeral planning into which any particular problem may be manipulated. Such a general formulation is afforded by the general arrangement shown in Fig. 4.

The signals are: $\mathrm{u}$ the sovereignty variables, $\mathrm{v}$ the measured variables, $w$ the exogenous signals such as disturbances $\mathrm{w}$ and domination $\mathrm{r}$ and $\mathrm{z}$ the so-called "error" signals which are to be minimized in some way to meet the dominion objectives. The industrial robot arm with $\mathrm{H} 2$ optimal controller block diagram is shown in Fig. 5.

\section{RESULTS AND DISCUSSION}

Open loop response: The open loop impulse and step response of the industrial robot arm for elbow angle and angular velocity and wrist angle and angular velocity with a current input of $10 \mathrm{~A}$ is shown in Fig. 6 and 7 respectively ${ }^{[3]}$. 


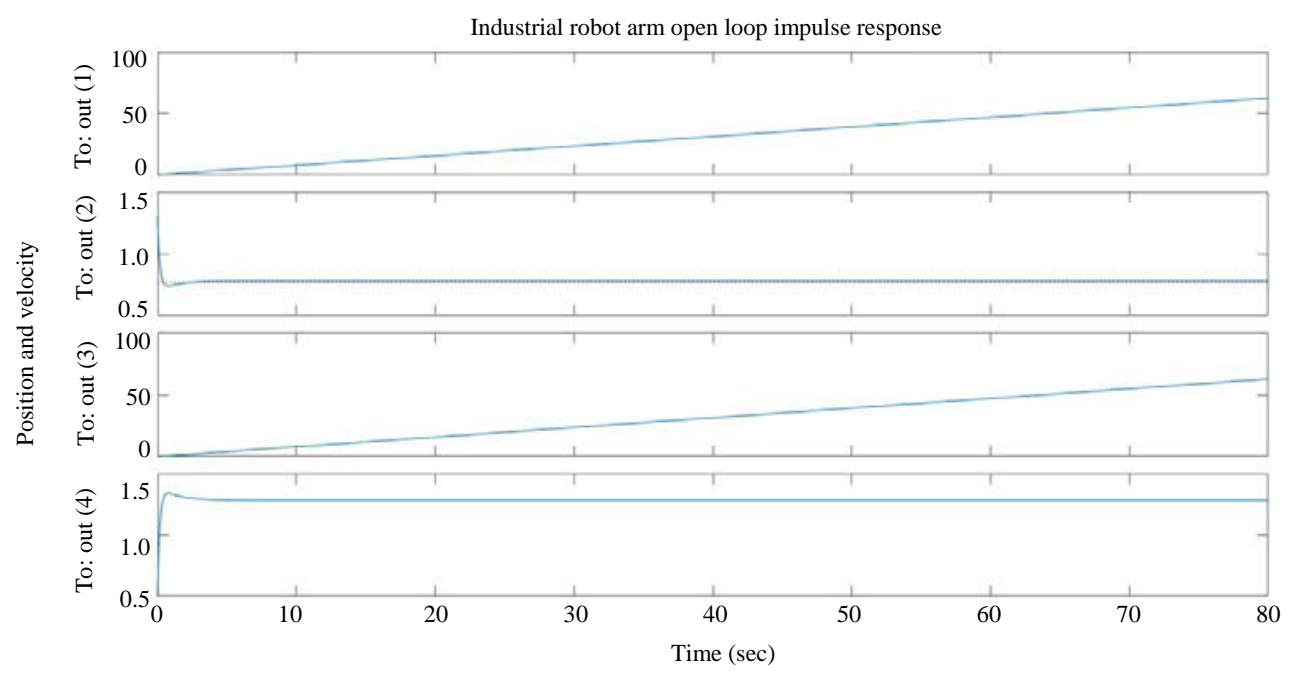

Fig. 6: Open loop impulse response

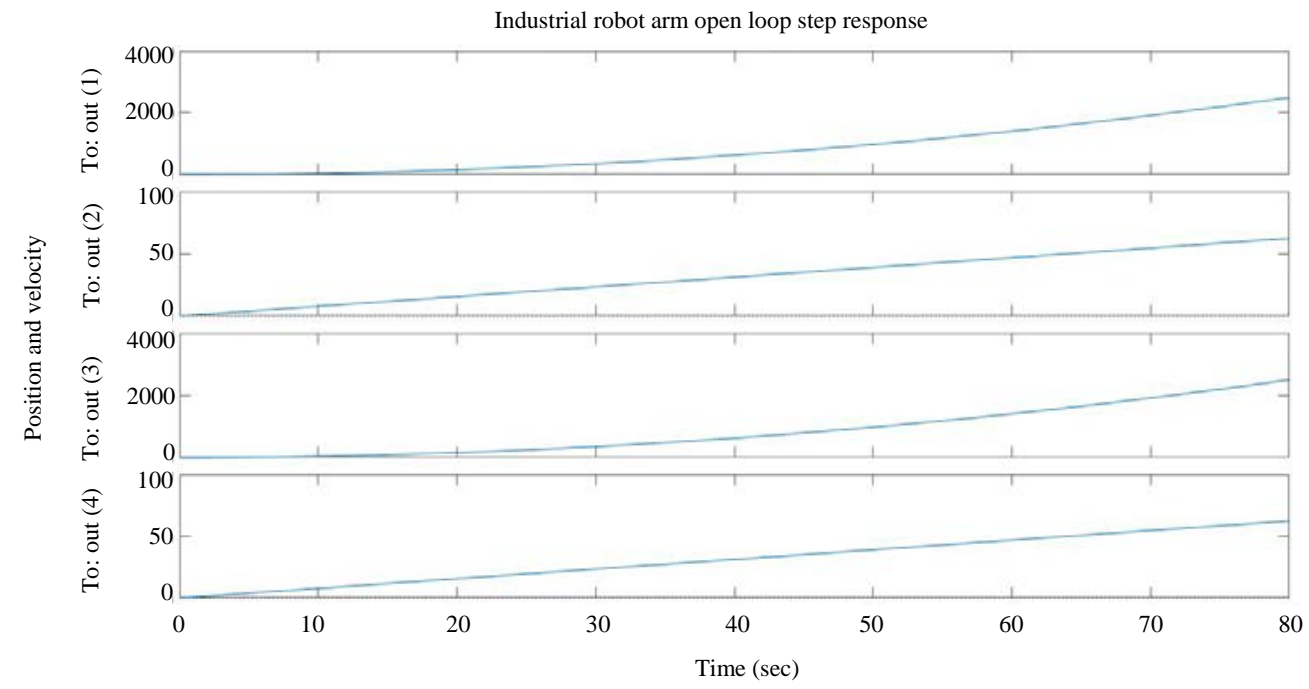

Fig. 7: Open loop step response

The open loop impulse response simulation shows that the elbow and wrist angle increases linearly and not settled but the elbow and wrist angular velocity have been settled to some values ${ }^{[4]}$.

The open loop step response simulation shows that the elbow and wrist angle and angular velocity increases linearly and not settled.

Comparison of the industrial robot arm with mixed $H 2 / H_{\infty}$ and $H 2$ optimal controllers for impulse and step input signals: The Comparison of the industrial robot arm with mixed $\mathrm{H} 2 / \mathrm{H}_{\infty}$ and $\mathrm{H} 2$ optimal controllers for an impulse and step input signals for elbow angle and angular velocity and wrist angle and angular velocity with a current input of $10 \mathrm{~A}$ is shown in Fig. 8 and 9 respectively.

The impulse response comparison shows that the elbow and wrist angles and velocities are affected by the impulse input current but the industrial robot arm with mixed $\mathrm{H} 2 / \mathrm{H} \infty$ shows a good performance in minimizing the settling time ${ }^{[5]}$.

The step response comparison shows that the elbow and wrist angles are controlled with a better settling time and the elbow and wrist angular velocities shows a good settling times but the industrial robot arm with mixed $\mathrm{H} 2 / \mathrm{H} \infty$ shows a good performance in minimizing the settling time and overshot ${ }^{[6]}$. 


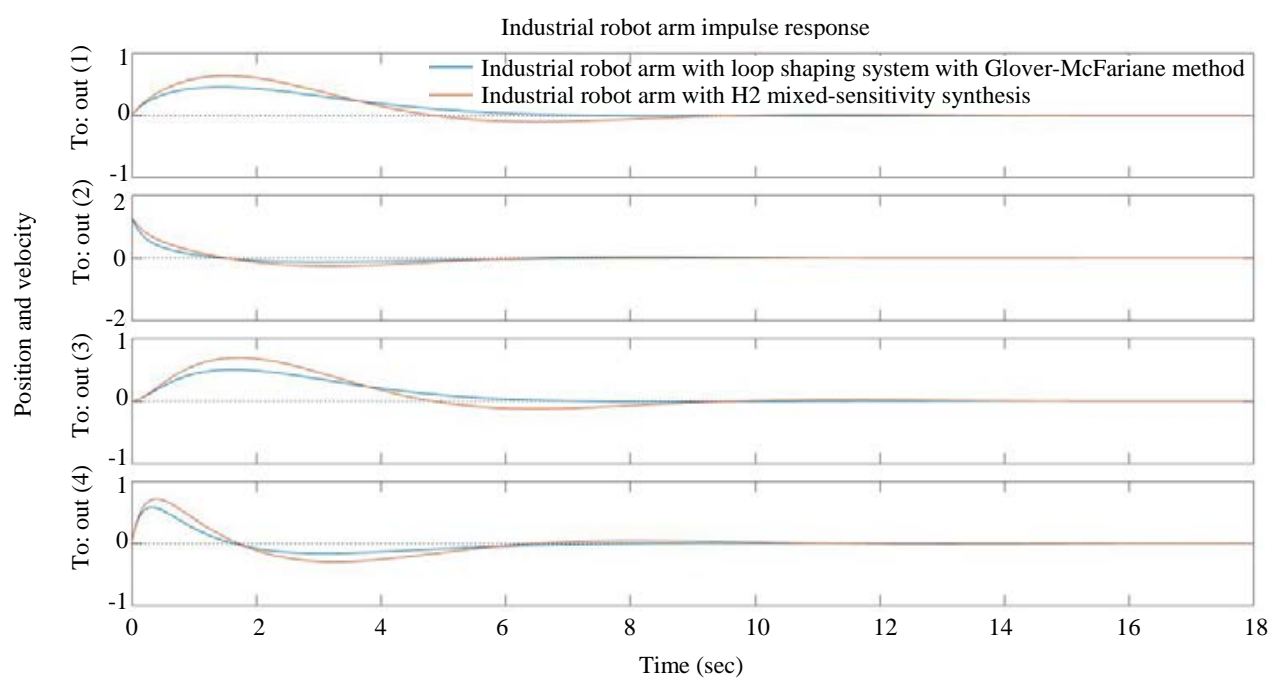

Fig. 8: Impulse response comparison

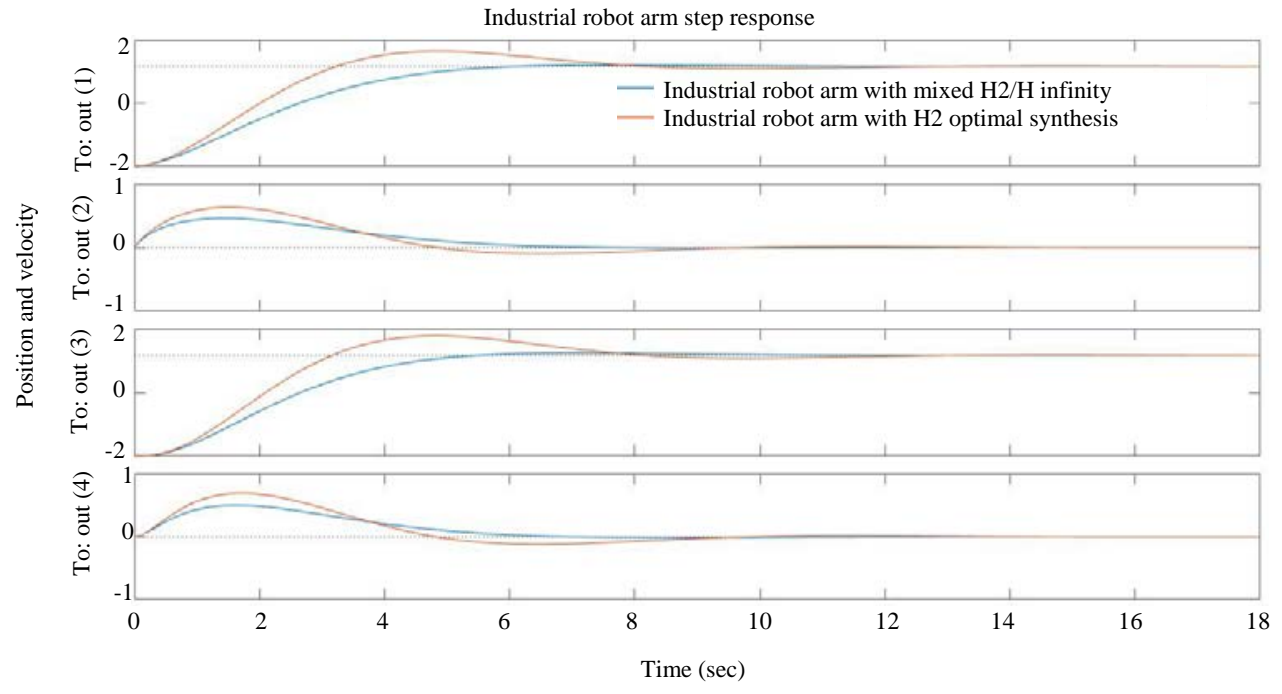

Fig. 9: Step response comparison

\section{CONCLUSION}

In this study, a 2 DOF industrial robot arm is modeled and designed for performance improvement using mixed $\mathrm{H} 2 / \mathrm{H} \infty$ synthesis with regional pole placement and $\mathrm{H} 2$ optimal controllers with the aid of MATLAB/Script Toolbox. The open loop response of the robot arm shows that both the elbow and wrist angles and velocities need to be improved. Comparison of the system with the proposed controllers have been done for an impulse and step input current signals. Finally, the comparison simulation results proved that the proposed mixed $\mathrm{H} 2 / \mathrm{H}_{\infty}$ synthesis with regional pole placement controller improves the robot arm angle and velocity better than the proposed $\mathrm{H} 2$ optimal controller ${ }^{[7,8]}$.

\section{REFERENCES}

01. Swamardika, I.A., I.N. Budiastra, I.N. Setiawan and N.I. Er, 2017. Design of mobile robot with robotic arm utilising microcontroller and wireless communication. Int. J. Eng. Technol. (IJET.), 9: 838-846.

02. Jiang, L., B. Gao and Z. Zhu, 2017. Design and nonlinear control of a 2-DOF flexible parallel humanoid arm joint robot. Shock Vibr., Vol. 2017, $10.1155 / 2017 / 2762169$

03. Huseyinoglu, M. and A.B.U.T. Tayfun, 2018. Dynamic model and control of 2-dof robotic arm. Eur. J. Tech., 8: 141-150. 
04. Jiang, H., Z. Wang, Y. Jin, X. Chen and P. Li et al., 2020. Design, control and applications of a soft robotic arm. Int. J. Rob. Res., Vol. 12, Issue 1.

05. Chaudhary, H., V. Panwar, R. Prasad and N. Sukavanam, 2016. Adaptive neuro fuzzy based hybrid force/position control for an industrial robot manipulator. J. Intell. Manuf., 27: 1299-1308.

06. He, W., Y. Dong and C. Sun, 2015. Adaptive neural impedance control of a robotic manipulator with input saturation. IEEE. Trans. Syst. Man Cybern. Syst., 46: 334-344.
07. Kayani, B., S. Konan, J. Tahmassebi, J.R.T. Pietrzak and F. Haddad, 2018. Robotic-arm assisted total knee arthroplasty is associated with improved early functional recovery and reduced time to hospital discharge compared with conventional jig-based total knee arthroplasty: A prospective cohort study. Bone Joint J., 100: 930-937.

08. Abut, T., 2016. Modeling and optimal control of a DC motor. Int. J. Eng. Trends Technol., 32: 146-150. 